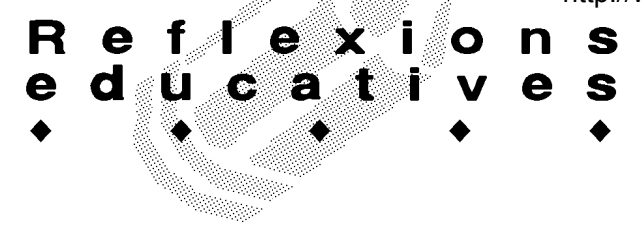

\title{
L'ADAPTACIÓ DELS CONTES POPULARS: LA CAPUTXETA VERMELLA
}

\author{
M. Àngels Ollé Romeu. Literatura Infantil i Juvenil
}

\section{La presència de Perrault}

Aquest any es celebra l'any Perrault. Especialistes i estudiosos de Literatura Infantil i Juvenil, ja que va ser l'any 1697 quan es va publicar el llibre Histoires ou Contes du temps passé, volen recordar després de 300 anys l'obra i la figura d'un dels escriptors que ha estat i està més present en la cultura infantil europea.

Els personatges i les trifulgues de contes com ara $\mathrm{La}$ bella dorment, El gat amb botes, La Ventafocs, Barbablava, En Polzet, En Riquet del plomall, La Caputxeta vermella, etc, formen part del nostre imaginari col-lectiu. Qualsevol adult europeu és capaç de recordar i reconèixer els protagonistes d'aquests contes, i la referència de les seves aventures són ja avui per avui imprescindibles per a descodificar alguns missatges que ens poden arribar des de la vessant popular, com ara els acudits: Sabeu on portava e/ cistellet la Caputxeta vermella? en els mateixos àmbits literaris, recordem la novel-la de Carmen Martín Gaite, Caperucita en Manhattan, per exemple.

I de tots els contes de Perrault -ja ho predeien els exemples anteriors- La Caputxeta vermella és el més popular. En el cas de molts pares novells, és quasi el primer conte que poden explicar sense perdre's, i a la majoria de nois i noies, tot i que el recorden bé, els és difícil saber qui, quan i com els el van explicar per primera vegada: tenen la sensació que el saben de sempre. I és que per a moltes persones els records de la narració oral d'aquest conte queden emmarcats amb la visió de les imatges d'un llibre o d'un film de dibuixos animats.

\section{Versions de la Caputxeta}

Però la profusió d'aquest conte no és un fet actual. L'any 1991 es va fer a la Biblioteca Infantil Santa Creu de Barcelona una exposició de llibres de la Caputxeta vermella, publicats en català o castellà entre els anys 1900-1939. Cal recordar que aquesta biblioteca té un fons històric molt important de Literatura infantil. En aquesta exposició, doncs, es van seleccionar 22 exemplars, alguns d'ells il.lustrats per Benejam, Lola Anglada, Rakman, Penagos (dels Cuentos de Calleja), Sánchez Tena, Mercè Llimona, Maria Claret, Apel-les Mestres, etc.

Segons Vilariño (1985), els anys 80 hi havia a la Biblioteca Nacional de Madrid 1200 fitxes, sota l'epígraf de
Perrault, però segons ell no arriben a 10 les traduccions que mereixen ser citades, com ara les de Coll y Vehi (1862); Federico de la Vega (1863); Teodoro Baró (1883); M.Teresa Vernet (1952); Eyheramonno y Pascual (1978); C. Martín Gaite (1980); Carmen Bravo-Villasante (1981).

I el cert és que, tot $i$ la popularitat $i$ el respecte que es té per l'obra de Perrault, els seus contes han estat adaptats i traduïts seguint criteris diversos, de manera que alguns textos semblen més una adaptació lliure que una traducció.

Així, dels textos que avui comptem en català trobem certes diferències de l'original de Perrault:

"Il était une fois une petite fille de village, la plus jolie qu'on eût su voir: sa mère en était folle, et sa mère-grand plus folle encore. Cette bonne femme lui fit faire un petit chaperon rouge qui lui seyait si bien, que partout on l'appelait le petit Chaperon rouge".

"Una vegada en un poble hi havia una nena, la més bonica que mai s'hagi vist. La seva mare estava boja per ella, i encara més n'estava la seva àvia, que li va fer una petita caputxa vermella que li esqueia tan bé, que tothom li deia la Caputxeta vermella". (Valls).

Un altre dels objectes que ha sofert més variacions ha estat el pany de la porta de casa de l'àvia:

"Tire la chevillette, la bobinette cherra."

"Tiba l'anella i la balda caurà." (Desclot).

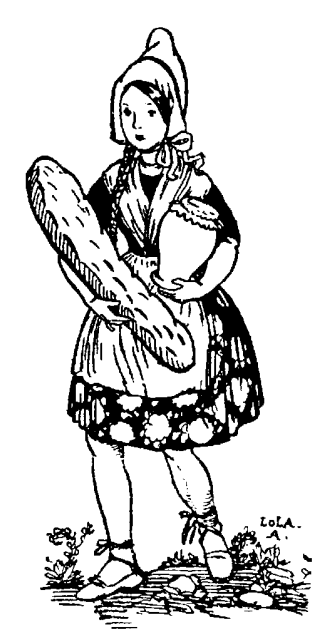

La Caputxeta vermella, de Lola Anglada. Associació Protectora de l'Ensenyança Catalana. Barcelona. 1933. 


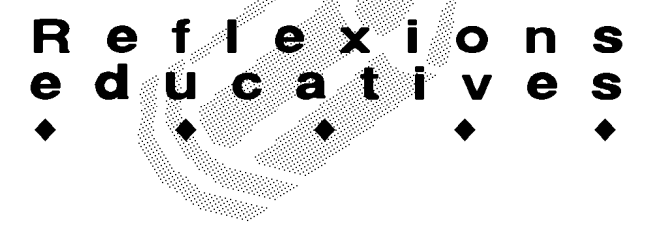

"Estira el pom i pujarà el baldó." (Valls).

Però Eyheramonno i Pascual ho tradueixen així:

"Tira de la aldabilla y caerá la tarabilla."

I afegeixen el comentari següent:

"La tarabilla es un zaquetillo o taruguillo de madera de forma cilíndrica, que se introduce en una cavidad de las jambas de la puerta y hace de cerrojo. Si a esta tarabilla se le ata a un extremo una cuerda que pase al exterior por un agujero de la puerta, tendremos el sistema de cerradura de la abuela de Caperucita, y que fue utilizado en la granjas campesinas."

Sembla difícil que un nen d' avui pugui fer-se càrrec d'aquest sistema de panys, però no deixa de ser més difícil que comprendre com es pot obrir una porta quan cau la balda.

Però les diferències més grans entre diverses versions estan precisament quan s'acaba la història, ja que hi ha dos detalls que sembla que s'han oblidat:

1) Els comentaris que fa la Caputxeta quan es posa al llit de l'àvia i la veu despullada:

"Le petit Chaperon rouge se déshabille et va se mettre dans le lit, où elle fut bien étonnée de voir comment sa mèregrand était faite en son déshabillé. Elle lui dit:

- Ma mère-grand, que vous avez de grands bras!

- C'est pour mieux t'embrasser, ma fille.

- Ma mère-grand, que vous avez de grandes jambes!

- C'est pour mieux courir, mon enfant.

- Ma mère-grand, que vous avez de grandes oreilles!

-C'est pour mieux écouter, mon enfant.

- Ma mère-grand, que vous avez de grands yeux!

-C'est pour mieux voir, mon enfant.

- Ma mère-grand, que vous avez de grandes dents!

-C'est pour te manger-. Et en disant ces mots, le méchant Loup se jeta sur le petit Chaperon rouge et la mangea."

La versió catalana en aquest mateix passatge diu:

"La Caputxeta vermella es va despullar i es va ficar al lit, tota parada de veure com era l'ávia sense vestit. I li va dir:

-laia, quins braços més llargs que teniu!

- Són per abraçar-te més bé, filla meva.

-laia, quines cames tan llargues que teniu!

- Són per córrer més bé, menuda meva.

-laia, quines orelles tan grosses que teniu!

- Són per escoltar-te més bé, petita meva.

-laia, quins ulls més grossos que teniu!

- Són per veure-hi més bé, menuda meva.

-laia, quines dents tan grosses que teniu!

-Són per menjar-te'm."

2) I afegeixen la figura del caçador:

"I, dient aquestes paraules, el malvat del Llop es va tirar sobre la Caputxeta vermella i se la va menjar." (Desclot).

El conte de Perrault acaba aquí: no hi ha un final feliç, no hi ha un caçador per salvar l' àvia i la néta.

Ès cert, però, que la majoria de nens han sentit la versió amb final feliç, i amb un estalvi important dels detalls del llit; quines, doncs, podrien ser les raons d'aquest afegitó i de l'oblit de les comparacions dels braços i les cames?

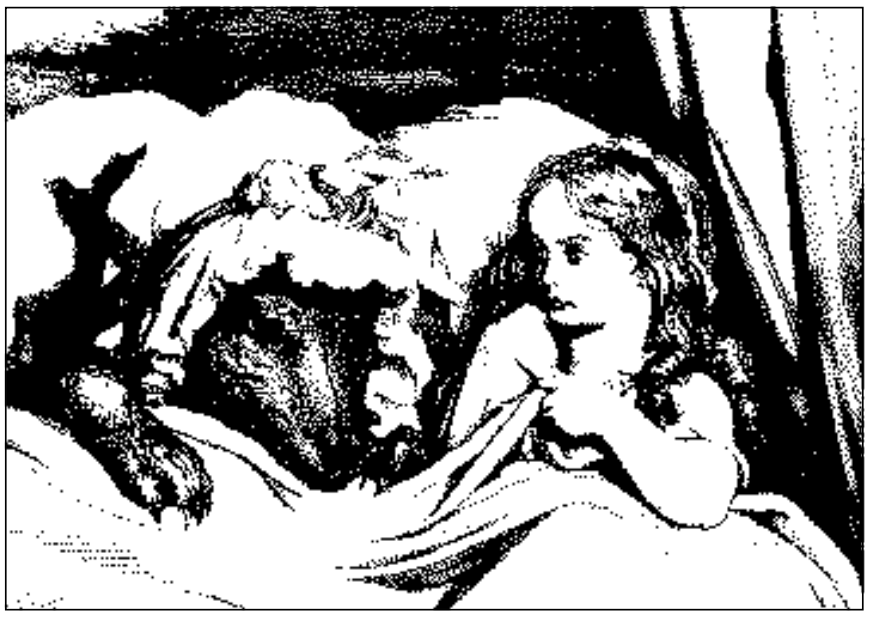

La Caperucita roja, de Charles Perrault. Cuentos de Antaño. Editorial Anaya. Madrid. 1983.

\section{Efectes "moralitzants"}

L'any 1812 es va publicar el primer volum del recull de contes, realitzat pels germans Grimm: Contes dels nens i de la llar, on hi ha una versió de la Caputxeta amb unes variacions que són precisament les que han fet fortuna en les narracions orals i que han contribuït possiblement a desorientar els adaptadors i traductors poc seriosos. Els dos elements que hem citat anteriorment queden descrits d'aquesta manera:

La caputxeta va ser regalada per l'àvia.

Quan el llop truca a la porta de casa de l'àvia, aquesta solament li diu: "Mou el pom de la porta."

I l'escena del llit queda resolta amb el comentari següent: "Sóc jo, iaia, la Caputxeta -va cridar-. Però ningú va contestar. Ella que sí, que s'acosta al llit i quan la veu, diu:"

El caçador, que precisament passava per allí en aquell moment, va pensar: "Com ronca la velleta: hauries d'anar a veure si necessita res." Quan va veure el llop, el va voler matar amb l' escopeta, però va pensar que potser s'havia menjat la velleta i encara la podrien salvar; així és que, amb unes tisores li va obrir la panxa i d'allà van sortir la Caputxeta i la seva àvia. Li van omplir la panxa de pedres, però aquest, quan es va despertar, va voler saltar i es va morir."

Vet aquí el final feliç que tothom recorda i que transmetem oralment. Sembla, doncs, que els primers culpables podrien ser els germans Grimm, ja que al ser el seu recull posterior al de Perrault podien haver-hi afegit la figura del caçador, escurçar i variar l'escena del llit, així com alguns altres detalls; tot plegat, molt adient a la moral puritana dels centreuropeus de l' època.

O potser la figura del caçador ja existia en el conte oral que va recollir en Perrult, però ell no la va voler fer servir perquè els seus criteris sobre el valor educatiu $i$, en aquest cas, moralitzador dels contes, passaven per creure que la 


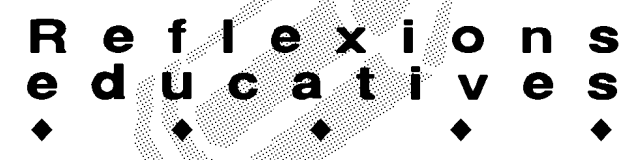

por viscuda a partir de una narració podia ser un advertiment seriós per a l'educació moral dels adolescents.

Aquesta raó podria justificar, doncs, el fet estrany que La Caputxeta vermella sigui l'únic conte, dels coneguts com a merevellosos, que té un final trist. Segons Paul Delarue, citat per Pascual, aquest no és pas un conte per instruir, sinó per advertir, fer por als nens per evitar perills. Si aquesta va ser la perspectiva de Perrault, contrasta amb els valors educatius de la majoria de contes meravellosos amb final feliç, ja que, segons Bettelheim, els contes de fades tenen com a objectiu no pas atemorir els nens, sinó alliberar-los de les seves angoixes.

Però Perrult sembla implacable: a més a més del final cru i dur, hi afegeix un poema on resumeix la seva intenció d'advertiment i amonestació:

On voit ici que de jeunes enfants,

surtout de jeunes filles

Belles, bien faites et gentilles,

Font très mal d'écouter toute sorte de gens,

Et que ce n'est pas chose étrange,

S'il en est tant que le loup mange,

Je dis le loup, car tous les loups

Ne sont pas de la même sorte:

II en est d'une humeur accorte,

Sans bruit, sans fiel et sans courroux,
Qui privés, complaisants et doux,

Suivent les jeunes demoiselles

Jusque dans les maisons, jusque dans les ruelles;

Mais hélas! qui ne sait que ces loups doucereux,

De tous les loups sont les plus dangereux.

Qui recorda aquests versos? Fins i tot alguns bons adaptadors de Perrault obliden el poema final; o d' altres

l'inclouen, però amb una traducció una mica lliure:

Hom veu aquí que els innocents infants,

I sobretot la nena d'ulls brillants,

Bonica, delicada i tan desperta,

No han de restar parats, la boca oberta,

Per escoltar tothom qui els ve a parlar:

No fos el llop en cerca de menjar.

$\mathrm{Hi}$ ha llops i llops de bona i mala pasta;

No són pas tots de la mateixa casta.

N'hi ha que són simpàtics i bons jans,

I riallers, sol-lícits i galants.

Que van seguint les nenes confiades

Fins que s'hi fan tot d'una a queixalades,

Però, ai!, qui no sap que els llops melosos,

De tots els llops, són els més perillosos? (Àlvar Valls).

D'altres, però, no ofereixen pas una traducció tan cesurada; recollim aquí la que fa C. Martín Gaite:

Aquí vemos cómo los jóvenes

$Y$ sobre todo las jóvenes

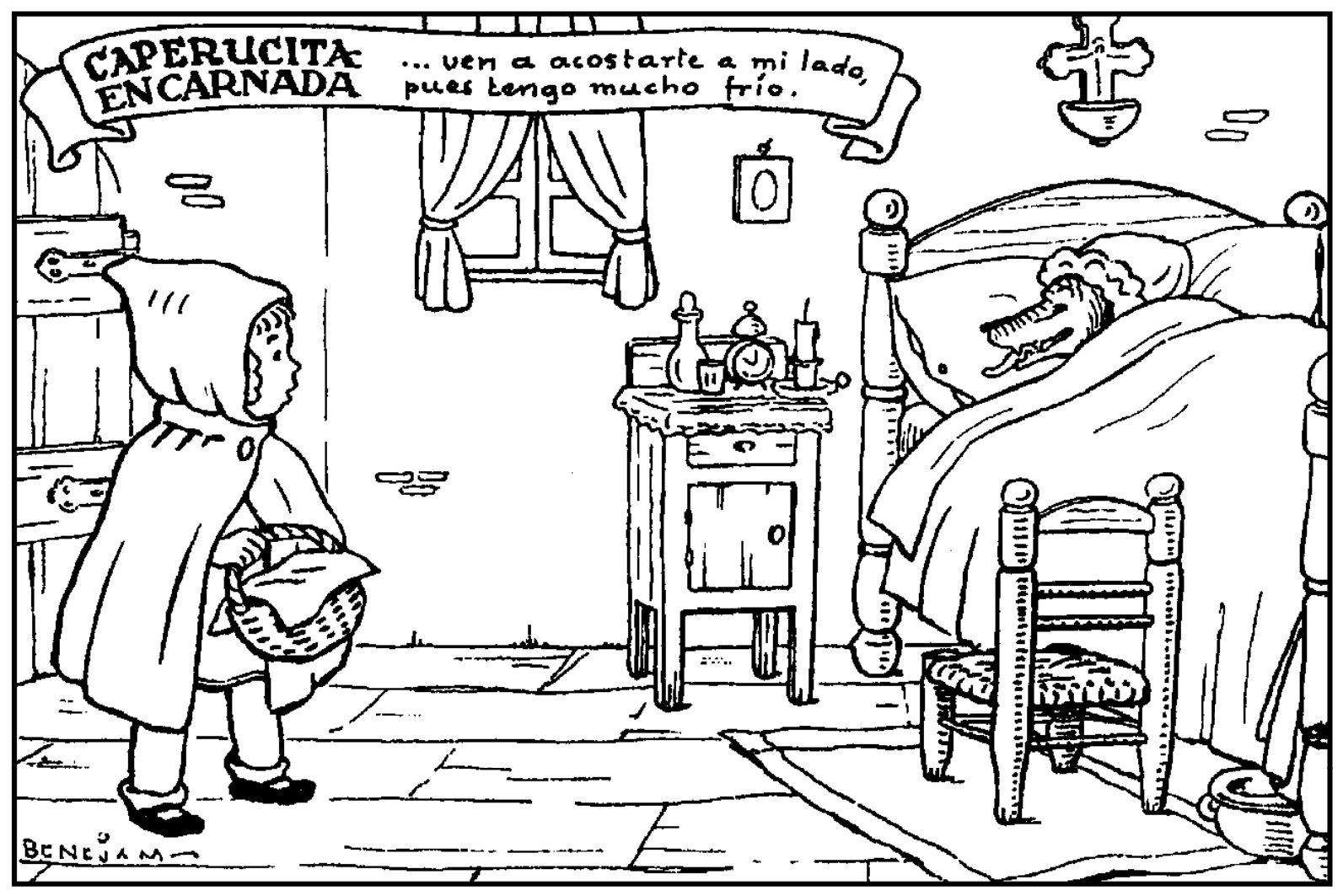

La Caperucita encarnada, de Benejam. TBO. Barcelona. sense data. 


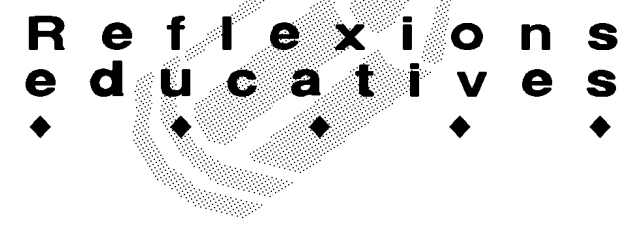

Guapas, de buen talle y amables

Hacen mal prestando oídos a cualquier clase de gente

$Y$ que no tiene nada de raro,

Si a tanats el lobo se come

Digo el lobo, porque no todos los lobos

Son de la misma especie:

Los hay de humor paciente,

Sin escándalo, sin hiel y sin cólera,

Que amaestrados, complacientes y dulces,

Siguen a las señoritas

Hasta en las casas y por las callejuelas,

Pero, jay!, ¿quién no sabe que estos lobos dulzones

Son los más peligrosos de todos los lobos?

\section{Una interpretació psicoanalítica}

Potser la voluntat moralitzadora de Perrult es va quedar, com a adult que era, amb els fets puntuals de la història i no va volorar els aspectes simbòlics dels mateixos personatges $\mathrm{i}$ situacions, com ara l'atracció de la bellesa física; el reclam sexual del color vermell; el voler i no poder de la Caputxeta, que té la bellesa i atractiu sexual, però no l'edat; el papers dels adults, imprudents $\mathrm{i}$ aprofitats de la ingenuïtat infantil, i va fer l'acabament de la història més real i trist.

Per què amb poema o sense poema, amb caçador 0 sense, quan expliquem el conte de la Caputxeta no estem parlant d'un comportament humà tan antic com reprobable, la violació, i els jocs que la poden provocar, la voracitat oral i els desitjos agressius i sexuals de la pubertat?

Ara podem fer aquestes reflexions de la mà de la psicoanàlisi, i podem trobar la raó per la qual els contes encara avui-tot i les grans innovacions tecnològiques-són escoltats, mirats, llegits, etc., és a dir, desitjats pels nostres nens. Perquè ells, com diu en Bettelheim, intuïtivament capten el seu significat, i cada conte els aporta de manera simbòlica experiències decisives per a la seva vida. Cada conte fa viure diferents detalls del comportament humà, i permet alliberar angoixes inicials -por, enveja, inseguretat, abandó, etc.-; iniciar l'estructuració dels seus sentiments -amor, odi, ennyorança, etc.-; descobrir l'existència de normes, costums i creences de la vida humana; fer de protagonista de moltes cerimònies d'iniciació.

I totes aquestes experiències, viscudes amb l'ajut de la paraula i de la imaginació, van recollint informació, van donant pistes sobre el fet que interessa més l'infant: créixer. I com que cada conte meravellós és una història d'iniciació, el petit oient va vivenciant que per créixer, o sigui, ser adult, li caldrà marxar de casa, superar sol moltes proves i dificultats, que si està atent, trobarà algun personatge que l'ajudarà, podrà superar totes les proves i podrà arribar al final feliç desitjat.

La Caputxeta vermella de Perrault no ha estat atenta, s'ha deixat entabanar per un llop, les flors, el plaer; la mare no li ha fet cap amonestació sobre els perills del bosc $\mathrm{i}$ l'àvia, precisament, li ha regalat una caputxa vermella, per fer-la més bonica i per tant, centre d'atracció fàcil.

Per a Perrault és just una situació com aquesta la que demana tota classe de reprovacions, i ell opta per la més dura: la mort, la desaparició. Per contra, els germans Grimm ens donen dues versions: la primera és la més popular, però totes dues amb la figura del caçador, que permetrà que tornin àvia i néta a la vida i que la protagonista pugui fer una reflexió final positiva i aprengui la lliçó.

Actualment, els contes meravellosos, com moltes obres clàssiques de la literatura infantil i juvenil, arriben als nens no pas pels canals tradicionals -narració i lectura-, sinó per altres mitjans de comunicació, com la ràdio, el cinema o la televisió. Possiblement ha estat la popularitat d'aquests contes el que els ha fet entrar en canals de comunicació nous, i precisament aquests nous mitjans són els que els estan mantenint presents. I així com passa en la trasmissió oral o escrita dels contes, on cada narrador dóna importància, treu detalls, en magnifica d'altres, etc. segons els seus gustos, així les factories especialitzades en dibuixos animats han explicat els contes populars amb la seva particular interpretació. I amb certa recança els adults veiem com molt ràpidament es desvirtuen, reutilitzen, etc. personatges dels contes meravellosos, i nohi podem pas fer res: són grans factories que de sobte popularitzen versions de contes on és difícil de trobar el guió original.

No sabem pas què en quedarà d'aquests contes, i ni tan sols ens podem imaginar quina versió del conte de La Caputxeta vermellatindrà supervivència, o quines empremtes deixarà la seva història en la cultura dels infants dels anys 2300, per exemple. En tot cas, tímidament podrà quedar constància del servei que ens van fer fins a l'acabament d'aquest mil.lenni.

\section{Bibliografia}

BETTELHEIM, B. Psicoanálisis de los cuentos de hadas. Editorial Grijalbo. Barcelona. 1984.

BETTELHEIM, B. Los cuentos de Perrault. Editorial Grijalbo.

Barcelona. 1987.

DESCLOT, M. Vet-ho aquí. Editorial Onda. Barcelona. 1981. HÜRLINMAN, B. Tres siglos de Literatura Infantil Europea.

Editorial Juventud. Barcelona. 1986.

GRIMM, J. i W. La Caputxeta vermella. Editorial La Galera.

Barcelona. 1983.

GRIMM, J. i W. Cuentos de los niños i del hogar. Editorial Anaya. Madrid. 1985.

MAÑÀ, T. 22 Caperucitas. «Revista CLIJ». 30,4 (1991) 42-49.

PERRAULT, C. Contes de Perrault. Edicions L'école des loisirs. París. 1978.

PERRAULT, C. La bella dorment i altres contes. Edicions de l'Abadia de Montserrat. Barcelona. 1983.

PERRAULT, C. Cuentos de Antaño. Editorial Anaya. Madrid. 1986.

SORIANO, M. Guide de Litérature pour la jeunesse. Editorial Flammarion. Paris.1975.

VILARIÑO, M. Noticia Bibliográfica. Cuentos de antaño. Editorial Anaya. Madrid. 1985. 